\title{
Lojistik Regresyon Modeli İle Finansal Başarısızlık Tahminlemesi : Borsa İ́stanbul'da Faaliyet Gösteren Gıda, İçki Ve Tütün Şirketlerinde Uygulama
}

\author{
Kerem URAL* \\ Şevin GÜRARDA** \\ M. Burak ÖNEMLI'***
}

\section{ÖZET}

Global ölçekte yaşanan ekonomik krizler, değişken ve zorlu iç ve diş ekonomik koşullar ile rekabetçi ortama ayak uyduramayan firmalar, mali ve ekonomik sıkıntılarla karşılaşmakta hatta iflasa kadar sürüklenmektedir. Firmaların bu ă̆ır rekabet koşulları altında varlıklarını sürdürebilmeleri için finansal sıkıntıların önceden tahmin etmeye yardımcı olacak modeller oldukça önem kazanmaktadır. Bu çalışma Borsa İstanbul'da işlem gören gıda, içki ve tütün şirketlerinin 2005-2012 yılları arası verilerini dikkate alarak finansal başarısızlık riskini lojistik model yardımıyla üç yıl öncesinden tahmin etmeyi hedeflemiştir. Finansal başarısızlı̆̆ın 1 yıl öncesinden öngörülmesini amaçlayan modelin öngörü gücü \%91, 2 yıl öncesinden tahminlemeyi hedefleyen modelin öngörü gücü \% 91 ve 3 yıl öncesinden öngörülmesini amaçlayan modelin öngörü gücü ise \%74,5'dir. Bu sonuçlar lojistik regresyon modelinin işletme başarısızlıklarında önemli bir araç olarak kullanılabileceğini göstermektedir. Bu çalışmada geliştirilen model; işletme yönetimine, yatırımcılara, potansiyel yatırımcılara ve diğer şirket ilgililerine yapacakları değerlendirmeler için yararlı olacaktır.

Anahtar Kelimeler: Finansal Başarısızlık, Lojistik Regresyon Modeli, Rasyo Analizi, Finansal Başarısızlık Nedenleri.

JEL Sinıflandirması: G17, M49, G19.

Financial Failure Estimation By Employing Logistic Regression Model: Application On Food, Beverage And Tobacco Companies Listed On The Borsa İstanbul

\section{ABSTRACT}

Due to global financial crises, challenging and changing domestic and international economic conditions, the businesses that cannot gain competitive advantage by any reason face difficulties which eventually cause them to drift bankruptcy. Models for the prediction of financial distress fort he survive of the companies under these conditions are gaining are gaining considerable importance. In this paper it is aimed to predict financial distress of the companies by using financial reports of the firms listed on Borsa Istanbul under food beverage and tobacco industry by running logistic regression model for the period 2005-2012. The predictive power of the model for one year before, two years before and third years before is respectively $91 \%$, $91 \%$ and $74,5 \%$. These results support that logistic model in the prediction of financial distress can be a useful and important tool. The model developed in this study will be useful for the evaluation of the companies performed by business management, investors, potential investors and other financial information users.

Keywords: Financial Failure, Logistic Regression Models, Ratio Analysis of the Reasons for Financial Failure.

Jel Classification: G17, M49, G19.

\footnotetext{
${ }^{*}$ Kerem Ural, Yaşar Üniversitesi, Sosyal Bilimler Enstitüsü, kerem.ural2012@stu.gediz.edu.tr

** Yrd. Doç. Dr. Şevin Gürarda, Gediz Üniversitesi, İktisadi ve İdari Bilimler Fakültesi, sevin.gurarda@gediz.edu.tr

*** Yrd. Doç.Dr. M. Burak Önemli, Gediz Üniversitesi, İktisadi ve İdari Bilimler Fakültesi, burak.onemli@gediz.edu.tr
} 


\section{GíRiş}

Bugünün iş dünyasında, teknolojik gelişmelere paralel olarak gitgide önemini yitiren uluslararası sınırlar, firmaları daha rekabetçi bir ortamda çalışmaya zorlamaktadır. Bu rekabetçi ortama ek olarak zorlayıcı ekonomik koşullar firmaların mali sıkıntıya sürüklemektedir. Mali ve ekonomik sskıntıların çözülemediği durumlarda ise iflas kaçınılmazdır.

Ülke ekonomisinin temelini oluşturan kaynakların da düzgün bir şekilde kullanılmadığ anlamına gelen finansal başarısızlı̆̆ı öngörülebilmesi veya finansal açıdan başarısız olma ihtimali ile ilgili sinyallerin önceden fark edilmesi oldukça önemlidir. Bu yüzden finansal başarısızlık ile ilgili öngörü çalışmaları; işletme sahipleri, yatırımcılar, işletmeye fon sağlayan kuruluşlar, sigorta şirketleri gibi birçok kişi ve kurum için önemli bir karar aracı olmaktadır. Finansal başarısızlı̆ın önceden tahmininde belirli finansal oranlarla desteklenmiş modeller literatürde önemli bir yere sahiptir. Bu modeller; firmaların yatırım kararlarına ve planlarına ışık tutarak finansal alanda almaları gereken tedbirler için gerekli kritik değerlendirmelere katkı sağlar.

$\mathrm{Bu}$ çalı̧manın amacı; finansal başarısızlığın sebeplerini ortaya koymak ve finansal oran analizini kullanarak finansal başarısızlı̆̆ 1 lojistik regresyon modeli ile incelemektir. Bu bağlamda Borsa İstanbul (BİST) imalat sektörü içerisinde bulunan gıda, içki ve tütün şirketlerinin 2005-2012 yılları arasındaki mali verileri dikkate alınarak rasyolar hesaplanmıştır. Çalışmanın ikinci bölümünde finansal başarısızlık ve nedenleri hakkında kısaca bilgi verilmiştir. Üçüncü kısımdaki literatürün özetini, metodoloji ve sonuç takip etmektedir.

\section{FINANSAL BAŞARISIZLIK VE NEDENLERI}

Weitzel \& Jonsson (1989)'a göre başarısızlık, işletmenin çevresine uyum sağlamaması, durgunluk, örgütsel ölümlülük, iflas, çöküş, küçülme, işletme faaliyetlerinin sonlandırılması, kapanma ve benzeri olarak tanımlanmaktadır.

Başarısızlık süreci, işletmenin yer aldığ sonuçlanabileceği gibi, bulunduğu konumdan gerilemesine de sebep olabilir. Finans literatüründe yaygın olarak kullanılan finansal başarısızlık türleri ekonomik başarısızlık, işletme başarısızlığı, teknik acizlik, negatif net değere sahip olma ve iflas olarak sıralanabilir.

İşletmelerin finansal anlamda başarısızlıkları genellikle iç ve dış etkenlere bağlı olarak ikiye ayrılır. İşletmeler bulunduğu çevreyi etkilediği gibi bulunduğu çevreden de etkilenmektedir. İşletmeleri başarısızlı̆a götüren bazı faktörler işletmenin kontrolü dışında oluşmaktadır. İşletmeler bu tür faktörleri tamamen önleyemese de en aza indirmeyi hedeflemektedir. Bu faktörler; işletmenin faaliyet gösterdiği toplumsal çevre, işletmelerin faaliyetlerini sürdürdükleri yasal ve politik çevre, ekonomik şartların oluşturduğu ekonomik çevre, teknolojik gelişmeler ve doğal çevre olarak sıralanabilir. 
İçsel nedenlere bağlı başarısızlıkları işletme riski olarak tanımlanmaktadır ve bu içsel nedenlerin başında yetersiz işletme sermayesi, işletmenin aşırı derecede kısa vadeli borç yükümlülüğ̈̈ altına girmesi, bütçelerin kontrolündeki yetersizlik ve benzeri olduğu söylenebilir.

İşletmenin içsel başarısızlığı finansal olmayan nedenlere de bağlı olabilir. Firmaları başarısızlı̆ga sürükleyen finansal olmayan nedenlerin en önemlileri arasında firma yöneticilerinin bilgi ve tecrübe eksikliğinden kaynaklı kötü yönetim, örgüt içindeki çatışmalar, koordinasyonsuzluk, yeni ürünler geliştirip yeni pazarlara açılamama vb. sayılabilir.

\section{LITERATÜR TARAMASI}

Şirketlerin faaliyetlerini sağlıklı bir şekilde devam ettirebilmeleri açısından oldukça önemli olan finansal başarısızlık tahmini, yatırımcılar, kredi verenler, para ve sermaye piyasalarını yönetenler, devlet organları gibi çeşitli kullanıcılarına fayda sağlamaktadır.

Finansal başarısızlık tahmini çalışmaları ilk olarak 1929 yılında yaşanan dünya ekonomik buhranı sırasında meydana gelen şirket iflasları ile başlamıştır. Finansal başarısızlık tahminine yönelik yapılan ilk çalışma 1930'ların başında R.A.Fisher tarafından geliştirilen diskriminant analizidir. (Altman, 1968).

Finansal başarısılzlk tahmini konusunda yapılan modellerin gelişmesine en önemli katkılardan biri Beaver (1966) tarafindan yapılan işletmelerin 5 yıllık dönemlerini inceleyen çalışmadır. Beaver’a göre, kârlılık oranları, likidite oranları ve borç ödeme gücünü gösteren rasyolar finansal başarısızlık tahminlerinde kullanılabilecek temel ögelerdir. Tamari (1966) oranların yetersiz kalma ihtimaline karşı risk endeksi modeli oluşturmuş, işletmeleri puanlayarak finansal başarısızlığı öngörmeyi hedeflemiştir.

Altman (1968), 1946-1965 y1llarında iflas etmiş 33 şirket ve başarılı 33 şirketi eşlemeli örneklem alarak karşılaşıırmış; finansal başarısızlık tahmini açısından en iyi sonucu verdiğini tespit ettiği rasyolarla Z-Skor modelini oluşturmuştur. ${ }^{1}$ Finansal başarısızlığın tahmini ile ilgili literatürde önemli bir yere sahip olan bu model işletmelerin iflasını 1 yıl önceden \%95, 2 yll önceden \%72 oranında doğrulukla tespit etmiştir.

Edmister (1972) küçük ölçekli firmalardan oluşan veri setinde Amerika Birleşik Devletleri'ndeki 1954-1969 yılları arasında 32 başarısız ve 562 başarılı işletmeyi inceleyerek söz konusu firmalar için bir model geliştirmiştir. Bu modelde 19 oran üzerinden çoklu regresyon tahmini ile başarılı ve başarısız firmaların oluşturduğu grupların doğru sınıflandırma oranını \% 90'ın üzerinde bulmuştur. Ohlson (1980) ise lojistik regresyon yöntemini kullanarak geliştirdiği modeli ile $\% 96$ oranında başarılı sınıflandırma yapmıştır.

\footnotetext{
${ }^{1}$ Kullanılan rasyolar, çalışma sermayesi / toplam varlıklar, dağıtılmamış kar/ toplam varlıklar, faiz ve vergi öncesi kar / toplam varlıklar, işletmenin piyasa değeri / toplam borçlar, satışlar / toplam varlıklardır.
} 
Türkiye'de finansal başarısızlık alanında yapılan ilk çalışmalardan biri Ertuna (1978) 24 sanayi dalında faaliyet gösteren 195 işletmeyi 38 finansal oranla 1973-1975 yılları için incelemiş ve başarısızlı öngörüsü yönteminde değişkenlerin normal dağılım göstermediği sonucuna varmıştır. (Çelik, 2009 : 67).

Diskriminant analizinin kullanıldığı ilk çalışma olan Göktan (1981) 25 başarılı ve 14 başarısız işletmenin 1976-1980 yılları arasındaki mali verilerini dikkate alarak hesapladığı 19 finansal oran ile işletmelerin iflasından bir yıl öncesini \%92,9 oranında doğru tahmin eden bir model oluşturmuştur. Faktör analizi ve lojistik regresyon analizini kullanan Altaş ve Giray (2005) tekstil sektörünü temel aldıkları çalışmalarında doğru sınıflandırma oranını $\% 74,2$ olarak hesaplamışlardır. Lojistik regresyon analizinin uygulanması sonucunda 2001 yılında tekstil sektöründe faaliyet gösteren borsaya kote şirketlerin kayıtlı ilgili dönem sonundaki karzarar durumunu yani mali başarısızlığını belirleyen en önemli faktörün cari oran, asit-test oranı ve nakit oranı olduğunu saptamıştır.

$\mathrm{Bu}$ çalışmada da BİST imalat sektörü içerisinde bulunan gıda, içki ve tütün şirketlerinin 2005-2012 yılları arasındaki verileri dikkate alınarak lojistik regresyon modeli yardımıyla finansal başarısızlığın tahminlenmesi hedeflenmiştir.

\section{METODOLOJI}

$\mathrm{Bu}$ çalışmanın amacı işletmelerin içine düşebileceği finansal başarısızlıkları, finansal oranlar ve ikili lojistik regresyon yöntemi yardımıyla 3 yıl öncesine kadar tespit edilmesini sağlamaktır. Çalışmada BİST imalat sektörü içerisinde bulunan gıda, içki ve tütün şirketlerinin 2005-2012 yılları arasındaki mali verileri dikkate alınarak 27 finansal rasyo hesaplanmıştır. Analizimizin muhtemel bağımsız değişkenlerimiz olan bu rasyolar şunlardır:

$\mathrm{X}_{1}$ : Cari oran

$\mathrm{X}_{2}$ : Asit - test oran1 (likidite oran1)

$\mathrm{X}_{3}$ : Nakit oran

$\mathrm{X}_{4}$ : Stoklar / toplam varlıklar

$\mathrm{X}_{5}$ : Faaliyet sonucu sağlanan fon / kısa vadeli yükümlülükler

$\mathrm{X}_{6}$ : Toplam yükümlülükler / toplam kaynaklar

$\mathrm{X}_{7}$ : Kısa vadeli yükümlülükler/ toplam kaynaklar

$\mathrm{X}_{8}$ : Uzun vadeli yükümlülükler / toplam kaynaklar

$\mathrm{X}_{9}$ : Sermaye / toplam kaynaklar

$\mathrm{X}_{10}$ : Özkaynaklar / toplam kaynaklar

$\mathrm{X}_{11}$ : Özkaynaklar / toplam yükümlülükler

$\mathrm{X}_{12}$ : Duran varlıklar / özkaynaklar

$\mathrm{X}_{13}$ : Stok devir hizı 


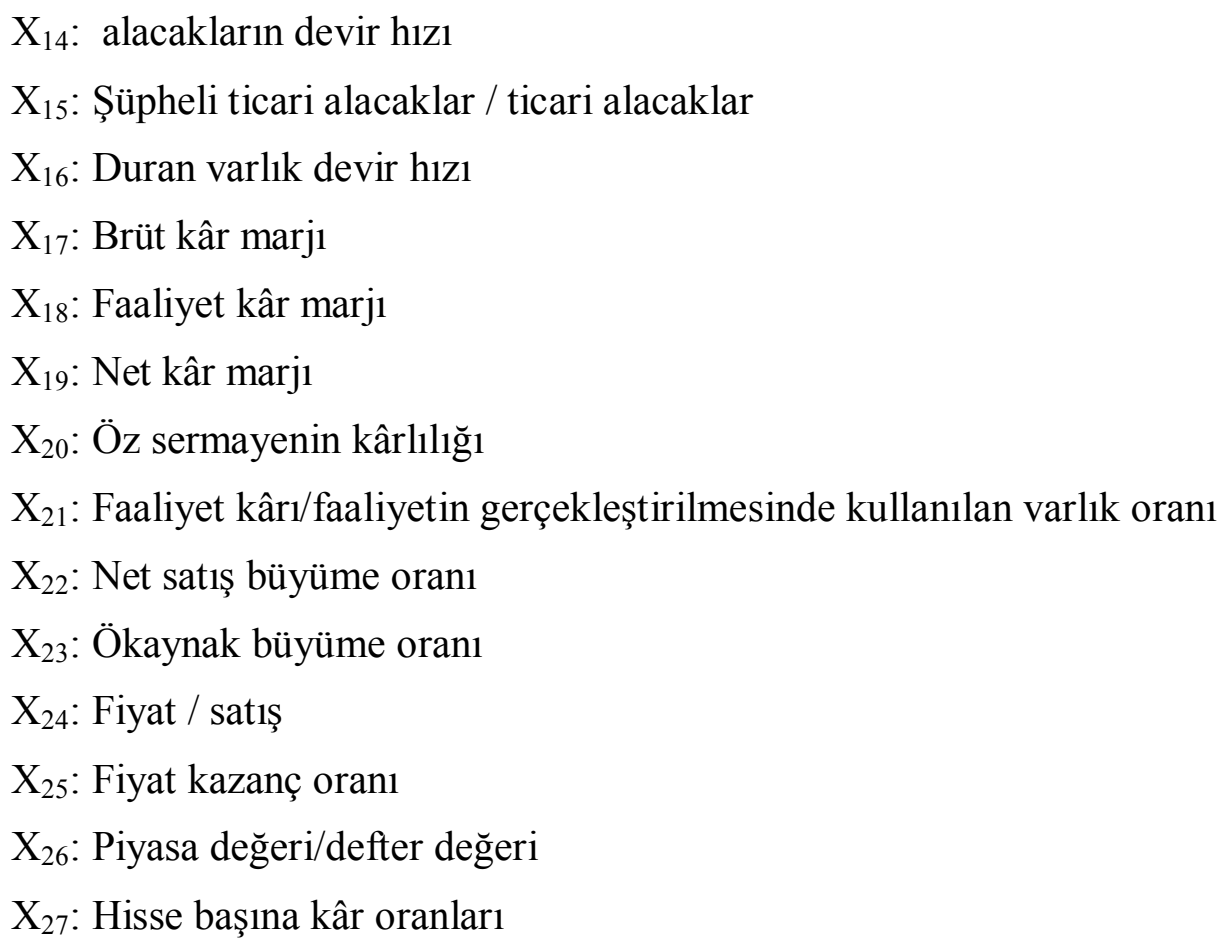

Sadece iflas sürecine girmiş şirketleri finansal açıdan başarısız olarak regresyona dahil etmenin çalışmayı daraltacağı düşünüldüğü için finansal açıdan başarısız sayılma kriterleri oluşturulmuştur. Bir şirketin finansal açıdan başarısız olarak sınıflandırılması için şu ölçütler kullanılmıştır: Son üç yılında şirketin zarar açıklaması, BİST’te işlem sırasının kalıcı olarak kapatılması, işletmenin özkaynaklarının negatif değerde olması, işletmenin BİST gözaltı piyasasına alınması, Faaliyetlerini durdurmuş olması, İflasını açılamış olması Bu kriterlerden herhangi birine uyan şirket, başarısız olarak sınıflandırılmıştır.

Çalışmada firma başarısızlıklarını tahmin edebilmek için lojistik regresyon analizi kullanılmıştır. Logit analiz olarak da adlandırılan lojistik regresyon analizi çok değişkenli bir istatistiksel analiz tekniğidir (Doğrul, 2009). Bu metodun temel amacı bağımlı değişkenin iki değeri arasındaki geçişliğine yol açan bağımsız değişken değerlerini olasılıklar ile tespit etmektir.

Lojistik regresyon tekniği, olasılık ve olasılıklar oranı (odds) kavramlarına dayanır. Olasılık, belirli bir tipteki sonuç sayısının ortaya çıkabilecek toplam sonuç sayısına oranıdır. Lojistik regresyonda olasılıklar oranı, bir olayın gerçekleşme olasılı̆̆ının gerçekleşmeme olasılığına oranı olarak tanımlanır. (Mertler \& Vannatta, 2005, s. 134). Bir başka ifadeyle olasıliklar oranı:

$$
\frac{p}{1-p}
$$


$\mathrm{Bu}$ orandaki $p$ bir olayın (başarı faktörünün) gerçekleşme olasılığını, $1-p$ ise söz konusu olayın gerçekleşmeme (başarısızlık faktörünün gerçekleşme) olasılığını gösterir. Olasılıklar oranı p'ye bağlı olarak 1'den büyük, küçük ve 1'e eşit olabilir. Bağımsız değişkenlerin farklı değerlerine bağlı olarak bağımlı değişkenin aldığı mümkün iki değerin her birinden hesaplanan olasılıklar oranlarının birbirine bölümü rölatif risk veya bahis oranı olarak adlandirılır.

Lojistik regresyon analizi doğrusal olmayan bir analizdir.. Lojistik regresyondaki anahtar kavram, "logit" kavramıdır. Logit, olasılıklar oranının logaritmasıdır. Buradan hareketle, tahmin edilecek lojistik regresyon modeli

$$
\log i t(p)=\log \frac{p}{1-p}=X^{i} \beta+u
$$

Şeklinde yazılabilir. Burada, $p$ bağımlı değişken için başarı faktörü olarak belirlenen durumun gerçekleşme oranı, $X k$ sayıdaki bağımsız değişkeni içeren $n \times(k+1)$ boyutundaki bağımsız değişken matrisi, $\beta(k+1) \times 1$ boyutundaki parametre vektörü, $u$ ise hata terimini ifade etmektedir.

Olasılıklar oranları yardımıyla her bir değişkenin bağımlı değişkenin başarı faktörü üzerindeki olasılığı, şu eşitlik yardımıyla elde edilebilir: (Mertler \& Vannatta, 2005, s. 135).

$$
p=\frac{\exp \left(X^{\prime} \beta\right)}{1+\exp \left(X^{\prime} \beta\right)}
$$

Çalışmada daha önce sıralanan başarısızlık kriterlerine bağlı olarak firmalar başarılı ve başarısız olarak ikiye ayrılmıştır. Lojistik regresyonun kategorik bağımlı değişkeni aşağıdaki şekilde sembolize edilmiştir.

$$
Y=\left\{\begin{array}{cl}
1, & \text { Finansal Olarak Başanlı Firmalar Için, } \\
0_{s} & \text { Finansal Olarak Başarısız Firmalar Için . }
\end{array}\right.
$$

Analizlerde ileri doğru adım adım seçme prosedürü (Stepwise Forward) kullanılmıştır. Önce sabitin yer aldığı model oluşturulmuş daha sonra modele katkısı en fazla olan bağımsız değişkenden başlamak yoluyla her adımda bir değişken eklenmiştir. (Beaver, 1966, Altman, 1968, Altaş ve Güray, 2005)

\section{Model 1: Bir Yıl Öncesine Göre Başarısızlık Tahmin Çalışması}

Model 1 finansal başarısızlığın bir yıl önceden tahmininde hangi rasyoların bize yol gösterici olduğunu bu rasyoların göreli önemleriyle birlikte ortaya koymaktadır. Tahmin edilen model bağımlı değişkenin en fazla faaliyet kâr marjından, hisse başına kardan, fiyat kazanç oranından, sermaye/toplam kaynaklar oranından ve kısa vadeli yükümlülükler/toplam kaynaklar oranından etkilendiği göstermiştir. Söz konusu model seçimi için ileri doğru adım adım seçme prosedürü kullanılmış; model seçiminde AIC (Akaike bilgi ölçütü) kullanılmıştır. En küçük AIC oranına sahip modelin AIC istatistik değeri 121,51 dir. 
Model 1'e yönelik tahmin Tablo 1'de sunulmuştur.

Tablo 1: Finansal Başarının 1Yıl Öncesi Rasyolarla Tahmini

\begin{tabular}{llll}
\hline & \multicolumn{1}{c}{$\begin{array}{c}\text { Tahmin Edilen } \\
\text { Katsayı }\end{array}$} & Standart Hata & Z Değeri \\
\hline Sabit & 0.6310 & 0.6115 & 1.032 \\
Fiyat Kazanç Oranı & $0.0006^{*}$ & 0.0002 & 2.516 \\
Faaliyet Kar Marjı & $0.1140 * * *$ & 0.0302 & 3.774 \\
Hisse Başına Kar & $0.0299 * * *$ & 0.0080 & 3.705 \\
$\begin{array}{l}\text { Sermaye/Toplam } \\
\text { Kaynaklar }\end{array}$ & $-0.0167 * *$ & 0.0060 & -2.77 \\
$\begin{array}{l}\text { Kısa Vadeli } \\
\text { Yükümlülükler/ Toplam }\end{array}$ & $-0.0165^{*}$ & 0.0067 & -2.449 \\
Kaynaklar & & & \\
\hline
\end{tabular}

$* \% 10, * * \% 5$ ve $* * * \% 1$ seviyesinde istatistiksel anlamlılığ göstermektedir. $\mathrm{X}_{25}$ fiyat kazanç oranı;

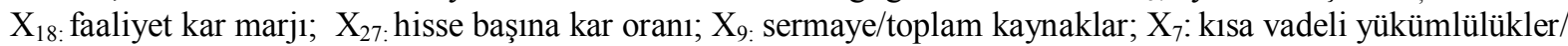
toplam kaynaklar.

Bir yıl öncesinden finansal başarısızlığa ilişkin tahminimiz:

$$
\begin{gathered}
\text { logit } Y_{t}=0,6311+0,0006 X_{25, t-1}+0,1140 X_{18, t-1}+0,0299 X_{27, t-1}-0,0167 X_{9, t-1} \\
-0,0165 X_{7, t-1}
\end{gathered}
$$

şeklindedir. Söz konusu modele göre finansal başarılı olma durumunun en büyük göstergesi faaliyet kar marjıdır. Modele göre exp.(0.0299)=1.030 diğer değişkenler sabitken firmanın hisse başına karında 1 TLlik artıştan kaynaklı finansal yönden başarılı olmaya yönelik rölatif risk oranını vermektedir. Benzer yorumlar diğer katsayılar içinde yapılabilir. Bu model kullanılarak, Borsa İstanbul'da işlem gören gıda, içki ve tütün şirketleri karşılaştırmaya tabi tutularak, başarı ve başarısızlık sınıflandırılmaları yapılmıştır. Bu sinıflandırmalara göre: örneğin, diğer tüm değişkenler sabitken AEFES şirketinin finansal başarısızlığa uğramama olasılığ $\% 99,15$ iken, söz konusu oran VANET için \%3,68'dir. Bir başka ifadeyle, söz konusu model uyarınca AEFES ve VANET firmalarının bir yıl gecikmeli rasyoları kullanıldığında AEFES firmasının finansal başarısızlık riskini \%0,85 olarak tahmin etmekteyken, bu riski VANET için \%96,32 olarak tahmin etmektedir.

Ayrıca, her bir firma için mevcut finansal başarı ya da başarısızlık durumu ve logit modelin bir yıl önceden öngördüğü finansal başarı ya da başarısızlık tahmini de Ek 1'de sunulmuştur. Buna göre, cari dönemden bir yıl öncesine dayalı model tahminin sınıflandırma başarısı \%91 olarak gerçekleşmiştir. Bir diğer ifadeyle, BİST'de işlem gören toplam 24 gıda şirketinin 22'si modelce doğru tahmin edilmiştir. Finansal yönden başarılı 14 firmanın 13'ü doğru tahmin edilmişken, finansal olarak başarısız 10 firmanın 9'u model tarafindan doğru sinıflandırmaya dâhil edilmiştir. 


\section{Model 2: İki Yıl Öncesine Göre Başarısızlık Tahmini}

Analizimizde, ikinci olarak, firmaların cari dönem finansal başarı ya da başarısızlığ1 iki yıl öncesi finansal oranları yardımıyla açıklanmaya çalışılmıştır. Bu bağlamda, amacımız finansal başarısızlığın iki yıl önceden tahmininde hangi rasyoların bize yol gösterici olduğunu ortaya koymaktır. İki yıl öncesine dayalı tahminde bağımlı değişken olan cari dönem başarısını en çok etkileyen oranlar ve bunların tahmin değerleri Tablo 2'de sunulmuştur. Söz konusu modelin AIC istatistiği 111,29'dur.

Tablo2: Finansal Başarının 2 Yıl Öncesi Rasyolarla Tahmini

\begin{tabular}{|c|c|c|c|}
\hline & $\begin{array}{l}\text { Tahmin Edilen } \\
\text { Katsayı }\end{array}$ & Standart Hata & Z Değeri \\
\hline Sabit & $-1.6819^{*}$ & 0.6291 & -2.673 \\
\hline Fiyat Kazanç Oranı & $0.0008^{* *}$ & 0.0003 & 2.976 \\
\hline Faaliyet Kar Marjı & $0.1332 * *$ & 0.0382 & 3.487 \\
\hline $\begin{array}{l}\text { Hisse Başına Kar } \\
\text { Oranı }\end{array}$ & $0.0168^{*}$ & 0.006 & 2.607 \\
\hline Asit Test Oranı & $0.0076^{* *}$ & 0.0038 & 1.967 \\
\hline $\begin{array}{l}\text { Duran Varlık Devir } \\
\text { Hızı Oranı }\end{array}$ & $0.0061^{*}$ & 0.0024 & 2.476 \\
\hline Cari Oran & $-0.0135^{* *}$ & 0.0044 & -3.024 \\
\hline $\begin{array}{l}\text { Özkaynaklar / } \\
\text { Toplam } \\
\text { Yükümlülükler }\end{array}$ & $0.0057^{*}$ & 0.0024 & 2.373 \\
\hline
\end{tabular}

* \% 10, ** \% 5 ve ***\%1 seviyesinde istatistiksel anlamlılı̆̆ 1 göstermektedir. $\mathrm{X}_{25}$ : fiyat kazanç Oranı ;

$\mathrm{X}_{18}$ : faaliyet kâr marj1; $\mathrm{X}_{27}$ : hisse başına kâr oranı $; \mathrm{X}_{2}$ :asit - test oranı; $\mathrm{X}_{16}$ : duran varlık devir hızı; $\mathrm{X}_{1}$ : cari oran $\mathrm{X}_{11}$ : öz kaynaklar / toplam yükümlülükler olarak ifade edilmiştir.

İki yıl öncesinden finansal başarısızlığa ilişkin modelimiz:

$$
\begin{gathered}
\log i t Y_{t}=-1,6819+0,0008 X_{25, t-2}+0,1332 X_{18, t-2}+0,0168 X_{27, t-2}+0,0076 X_{2, t-2} \\
+0,0061 X_{16, t-2}-0,0135 X_{1, t-2}+0,057 X_{11, t-2}
\end{gathered}
$$

şeklinde tahmin edilmiştir. Tahmin edilen modele göre, finansal başarılı olma durumunun en büyük göstergesi bir kez daha faaliyet kâr marjıdır.

Model 1'dekine benzer bir sınıflandırma model 2 için de yapılmıştır. Söz konusu, sınıflandırma uyarınca, örneğin PNSUT şirketinin finansal başarı olasılığı $\% 98,83$ ' tür. Öte taraftan, SKPLC firmasının finansal başarılı olma olasılığ1 \%45,08 olarak öngörülmüştür. Dolayısıyla, modelimiz PNSUT için finansal başarısızlık riskini \%1,17 olarak tahmin ederken, bu riski SKPLC için \%54,92 olarak öngörmüştür. Veri setimizdeki tüm firmalara ilişkin finansal başarısızlığa uğramama riskleri, her bir firma için mevcut finansal başarı /başarısızlık durumu ve logit modelin iki yıl önceden öngördüğü finansal başarı ya da başarısızlık tahmini ile birlikte Ek 2'de sunulmuştur. 
Tablo 2'ye göre, cari dönemden iki yıl öncesine dayalı model tahminin doğru sınıflandırma başarısı \%91 olarak gerçekleşmiştir. Bir diğer ifadeyle, Borsa İstanbul' da işlem gören toplam 24 gida şirketinin 22'si modelce doğru tahmin edilmiştir. Modelimizin finansal başarılı firmaları doğru kategorize etme oranı \%90 iken, finansal olarak başarısız firmaları doğru sınıflama oranı \%92 olarak gözlenmiştir.

\section{Model 3: Üç Yıl Öncesine Göre Başarısızlık Tahmin Çalışması}

Analizde son olarak finansal başarısızlığın üç yıl öncesinden tahmininde hangi rasyoların ne kadar açıklayıcı olduklarını ortaya koymak amaçlanmıştır. Tahmin sonucunda, nakit oranının, stoklar/toplam varlıklar oranının, brüt kar marjının, kısa vadeli yükümlülükler/ toplam kaynaklar oranının, şüpheli ticari alacaklar/ ticari alacaklar oranının, duran varlık devir hızının, alacak devir hızının ve piyasa değeri/ defter değeri oranının bağımlı değişken olan finansal başarıya ilişkin olasılıklar oranının logaritmasını en çok etkileyen değişkenler olduğu sonucuna ulaşılmıştır. Tahmin edilen model için AIC istatistiği 92,025'dir. Tahminler tablo 3'de sunulmuştur.

Tablo3: Finansal Başarının 3 Yıl Öncesi Rasyolarla Tahmini

\begin{tabular}{|c|c|c|c|}
\hline & $\begin{array}{l}\text { Tahmin Edilen } \\
\text { Katsayı }\end{array}$ & Standart Hata & Z Değeri \\
\hline Sabit & -1.3198 & 0.7722 & -1.709 \\
\hline $\begin{array}{l}\text { Duran Varlık } \\
\text { Devir Hızı }\end{array}$ & $0.012 * *$ & 0.0041 & 2.709 \\
\hline Nakit Oranı & $0.0977^{*}$ & 0.0422 & 2.313 \\
\hline $\begin{array}{l}\text { Şüpheli ticari } \\
\text { alacaklar / ticari } \\
\text { alacaklar }\end{array}$ & $-0.145^{* *}$ & 0.0494 & -2.843 \\
\hline $\begin{array}{l}\text { Kısa vadeli } \\
\text { yükümlülükler/ } \\
\text { toplam kaynaklar }\end{array}$ & $-0.0256 * *$ & 0.0093 & -2.744 \\
\hline Alacak Devir Hızı & 0.0007 & 0.0004 & 1.7811 \\
\hline $\begin{array}{l}\text { Piyasa Değeri/ } \\
\text { Defter Değeri }\end{array}$ & $-0.0014 *$ & 0.0006 & -2.314 \\
\hline Brüt Kar Marjı & $0.0365^{*}$ & 0.0185 & 1.975 \\
\hline $\begin{array}{l}\text { Stoklar / Toplam } \\
\text { Varlıklar } \\
\end{array}$ & $0.0564 *$ & 0.0276 & 2.039 \\
\hline
\end{tabular}

* \% 10, **\% 5 ve ***\%1 seviyesinde istatistiksel anlamlılığ göstermektedir. $\mathrm{X}_{16}$ : duran varlık devir hızı; $\mathrm{X}_{3}$ : nakit oranı; $\mathrm{X}_{15}$ : şüpheli ticari alacaklar / ticari alacaklar; $\mathrm{X}_{7}$ : kısa vadeli yükümlülükler/ toplam kaynaklar; $\mathrm{X}_{14}$ : alacakların devir hızı; $\mathrm{X}_{26}$ :piyasa değeri/defter değeri; $\mathrm{X}_{1}$ :brüt kâr marjı; $\mathrm{X}_{4}$ : stoklar / toplam varlıklar olarak ifade edilmiştir.

Üç yıl öncesinden finansal başarısızlığa ilişkin tahminimiz:

$$
\begin{gathered}
\text { logit } Y_{t}=-1,3198+0,012 X_{16, t-3}+0,0977 X_{3_{,} t-3}-0,145 X_{15, t-3}-0,0256 X_{7, t-3} \\
+0,0007 X_{14, t-3}+0,0365 X_{1, t-3}+0,0564 X_{4, t-3}-0,014 X_{26, t-3}
\end{gathered}
$$


şeklindedir. Söz konusu modele göre finansal başarılı olmanın üç yıl öncesinden tahmininde bağımlı değişkeni en fazla etkileyen oran nakit oranıdır.

İlk iki modelde olduğu gibi, tahmin sonucunda İstanbul'da işlem gören gıda, içki ve tütün şirketleri karşılaştırmaya tabi tutularak, başarı ve başarısızlık sınıflandırılmaları yapılmıştır. Bu sınıflandırmalara göre: örneğin, diğer tüm değişkenler sabitken MRTGG şirketinin finansal başarısızlığa uğramama olasılı̆̆ $\%$ 3,33 iken, söz konusu oran ULLKER için \%99,97'dir. Bir başka ifadeyle, MRTTG ve ULKER firmalarının üç yıl gecikmeli rasyoları kullanılarak yapılan tahminlere göre, MRTTG şirketinin finansal başarısızlığa uğrama riski \%96'dan fazlayken, bu oran ULKER için \%1'den daha düşüktür. Veri setimizdeki tüm firmalara ilişkin finansal başarısızlığa uğramama riskleri Ek 3'te sunulmuştur.

Ayrıca, her bir firma için cari dönem finansal başarı ya da başarısızlık durumu ve logit modelin üç yıl öncesine ait finansal oranlarına dayalı modelin öngördüğü finansal başarı ya da başarısızlık tahmini de Tablo 3'da sunulmuştur. Buna göre, cari dönemden üç yıl öncesine dayalı model tahminin sınıflandırma başarısı \%74,5 olarak gerçekleşmiştir. Modelimiz finansal olarak başarılı 19 firmanın 17'sini doğru kategorize ederken, finansal olarak başarısız olan 5 firmanın 3'ünü doğru sınıflandırmıştır.

\section{SONUÇ}

Şirketlerin, yaşanan ağır rekabet koşulları altında varlıklarını sürdürebilmeleri için finansal sıkıntıların önceden tahmin etmeye yardımcı olacak modeller oldukça önemlidir. $\mathrm{Bu}$ modeller şirketlerin, yatırımcıların ve fon sağlayıcıların firma başarısızlığını önceden tespit etmelerine ve işletmelerin gelecekteki durumları hakkında tahminlerde bulunmalarına yardımcı olarak şirket performanslarına bağlı maliyetlerin minimize edilmesine katkı sağlar. Bu çalışmada, 2005-2012 yılları arası BİST'de işlem gören gıda, içki ve tütün şirketlerinin yıllık finansal tablolarına dayalı rasyoları kullanılarak, söz konusu firmalara ait finansal başarısızlığın lojistik regresyon modeliyle öngörülmesi amaçlanmıştır. Analize dâhil edilen 27 oran yardımıyla, finansal başarısızlığın 1, 2 ve 3 yıl öncesinden tahmininde hangi oranların faydalı ipuçları sağladığı belirlenmeye çalışılmıştır.

Finansal başarısızlığın 1 yıl öncesinden öngörülmesini amaçlayan modele göre, fiyat kazanç oranı, faaliyet kar marjı, hisse başına kar oranı, sermaye/toplam kaynaklar oranı, kısa vadeli yükümlülükler/toplam kaynaklar oranı finansal başarı veya başarısızlığın temel göstergeleridir. Bu tahminin doğru sınıflandırma başarısı ya da modelin öngörü gücü \%91 olarak belirlenmiştir. Benzer şekilde, finansal başarısızlığın 2 yıl öncesinden tahmininde önemli göstergeler ise fiyat kazanç oranı, faaliyet kâr marjı, hisse başına kâr oranı, asit-test oranı, duran varlık devir hızı, cari oran, öz kaynaklar/toplam yükümlülükler oranı olarak belirlenmiştir. Söz konusu modelin doğru sınıflandırma oranı ise \% 91 olarak bulunmuştur. Son olarak, Finansal başarısızlığı 3 yıl öncesinden tahmin eden modele göre duran varlık devir hızı, nakit oranı, şüpheli ticari alacaklar/ticari alacaklar oranı, kısa vadeli 
yükümlülükler/toplam kaynaklar oran1, piyasa değeri/defter değeri, brüt kâr marjı ve stoklar/toplam varlıklar oranı finansal başarı ya da başarısızlığın temel göstergeleri olarak belirlenmiştir. Söz konusu lojistik regresyon modelinin sınıflandırma başarısının \% 74,5 olduğu görülmüştür

Tahmin ettiğimiz modellerin doğru sınıflama başarılarını göz önüne alarak, lojistik regresyon modeli tahminlerinin işletme finansal başarı ya da başarısızlığını önceden tespit etmede iyi bir araç olduğu söylenebilir. $\mathrm{Bu}$ çalışmada kullanılan modelin işletme yönetimlerine, yatırımcılara, potansiyel yatırımcılara, diğer şirket ilgililerine ve finansal tablo kullanıcılarına yapacakları değerlendirmeler için yararlı olacağını görüşündeyiz.

\section{KAYNAKLAR}

Altaş, Dilek ve Giray, Selay (2005), "Mali Basarısızlığın Çok Değiskenli İstatistiksel Yöntemlerle Belirlenmesi: Tekstil Sektörü Örneği”, Sosyal Bilimler Dergisi, Cilt 5, Say1 2 , s. $13-28$

Altman, Edward I. (1968), "Corporate Financial Distreess: A Complete Guide to Predicting, Avoiding and Dealing With Bankruptcy”, Journal of Finance, Vol 23, No 4, s.589609.

Çelik, Melike Kurtaran (2009), Finansal Başarısızlık Tahmin Modellerinden İMKB'deki Firmalar İçin Karşılaştırmalı Analizi, Doktora Tezi, s. 75-79.

Doğrul, Ümit (2009), Finansal Başarısızlık ve Finanasal Başarısızlık Tahmini:Hisse Senetleri İMKB'de İşlem Gören Sınai İşletmeler Üzerinde Bir Uygulama, Yüksek Lisans Tezi, Mersin Üniversitesi Sosyal Bilimler Enstitüsü, s.70-72.

Edmister, Robert O. (1972), “An Empirical Test of Ratio Analysis for Small Business Failure Prediction", Cambridge University Press, Vol 7, No 2, s. 1477-1493.

Ertuna, Özer İ. (1978), İmalat Sektörü Özel Kesiminde Mali ve Ekonomik Göstergeler (19731975) Bilrapor Sistemi, Boğaziçi Üniversitesi Yayınları, İstanbul

Göktan, Erkut (1981), Muhasebe Oranları Yardımıyla ve Diskriminant Analiz Tekniği Kullanarak Endüstri İşletmelerinin Mali Başarısızlığının Tahmini Üzerine Amprik Bir Araştırma, Doçentlik Tezi, s. 14.

Beaver, William H. (1966), "Financial Ratios as Predictors of Failure”, Journal of Accounting Research, Vol 4, s.71-111.

Tamari, Meir (1966) "Financial Ratios as a Means of Forecasting Bnakruptcy”, Management İnternational Review, Vol 6, No 4, s. 15-21.

Mertler, Craig A. ve Vannatta, Rachel A. (2005), Advanced And Multivariate Statistical Methods: Practical Application And İnterpretation (3rd Ed.), Pyrczak Publishing, Glendale, CA. 
Ohlson, James A. (1980), "Financial Ratios and Probabilistic Prediction of Bankrupty". Journal of Accounting Research, Vol 18, No 1, s. 109-131.

Weitzel, William ve Jonsson, Ellen (1989), "Dicline in Organizations: A Literature İntegration and Extension", Administarative Science Quarterly, Vol 34, No 1, s. 91109 . 
Ek 1: 1 Y1l Öncesine Göre Başarısızlık Tahmin Çalışması- Logit Tahmini Karşılaştırması

\begin{tabular}{|c|c|c|c|}
\hline FİRMALAR & $\begin{array}{l}1 \text { YIL ÖNCESINE } \\
\text { GÖRE ODDS } \\
\text { RASYOSU }\end{array}$ & $\begin{array}{c}\text { LOGITT TAHMINİ } \\
\text { BAŞARI }\end{array}$ & $\begin{array}{l}\text { BAŞARISIZLIK } \\
\text { DURUMU }\end{array}$ \\
\hline AEFES & 0,9915098 & 1 & 1 \\
\hline ALYAG & 0,02344759 & 0 & 0 \\
\hline BANVT & 0,910336 & 1 & 1 \\
\hline CCOLA & 0,9989232 & 1 & 1 \\
\hline DARDL & 0,7616995 & 1 & 1 \\
\hline ERSU & 0,2948842 & 0 & 0 \\
\hline FRIGO & 0,2325022 & 0 & 0 \\
\hline KENT & 0,9999984 & 1 & 1 \\
\hline KERVT & 0,4132584 & 0 & 0 \\
\hline KNFRT & 0,9671432 & 1 & 1 \\
\hline KRSTL & 0,3163336 & 0 & 0 \\
\hline MERKO & 0,9445054 & 1 & 1 \\
\hline MRTGG & 0,1411384 & 0 & 0 \\
\hline PENGD & 0,804598 & 1 & 1 \\
\hline PETUN & 0,9326093 & 1 & 1 \\
\hline PINSU & 0,9985972 & 1 & 1 \\
\hline PNSUT & 0,9910186 & 1 & 1 \\
\hline SELGD & 0,7997811 & 1 & 0 \\
\hline SKPLC & 0,001673768 & 0 & 0 \\
\hline TATKS & 0,9990591 & 1 & 1 \\
\hline TBORG & 0,816477 & 1 & 1 \\
\hline TUKAS & 0,09525718 & 0 & 0 \\
\hline ULKER & 0,9436722 & 1 & 1 \\
\hline VANET & 0,0368458 & 0 & 0 \\
\hline
\end{tabular}


Ek 2: 2 Y 1l Öncesine Göre Başarısızlık Tahmin Çalışması- Logit Tahmini Karşılaştırması

\begin{tabular}{|c|c|c|c|}
\hline FİRMALAR & $\begin{array}{l}2 \text { YIL ÖNCESINE } \\
\text { GÖRE ODDS } \\
\text { RASYOSU }\end{array}$ & $\begin{array}{c}\text { LOGIT TAHMINI } \\
\text { BAŞARI }\end{array}$ & $\begin{array}{l}\text { BAŞARISIZLIK } \\
\text { DURUMU }\end{array}$ \\
\hline AEFES & 0,9721019 & 1 & 1 \\
\hline ALYAG & 0,2862362 & $\mathbf{0}$ & $\mathbf{0}$ \\
\hline BANVT & 0,3091079 & $\mathbf{0}$ & 1 \\
\hline CCOLA & 0,9487969 & 1 & 1 \\
\hline DARDL & 0,006285419 & $\mathbf{0}$ & $\mathbf{0}$ \\
\hline ERSU & 0,1376818 & $\mathbf{0}$ & $\mathbf{0}$ \\
\hline FRIGO & 0,08289615 & $\mathbf{0}$ & $\mathbf{0}$ \\
\hline KENT & 1 & 1 & 1 \\
\hline KERVT & 0,000001414392 & $\mathbf{0}$ & $\mathbf{0}$ \\
\hline KNFRT & 0,9975988 & 1 & 1 \\
\hline KRSTL & 1 & 1 & 1 \\
\hline MERKO & 0,2942792 & $\mathbf{0}$ & $\mathbf{0}$ \\
\hline MRTGG & 0,01353673 & $\mathbf{0}$ & $\mathbf{0}$ \\
\hline PENGD & 0,06400332 & $\mathbf{0}$ & $\mathbf{0}$ \\
\hline PETUN & $\mathbf{0 , 8 8 5 0 7 1}$ & 1 & 1 \\
\hline PINSU & 0,2934584 & $\mathbf{0}$ & $\mathbf{0}$ \\
\hline PNSUT & 0,988341 & 1 & 1 \\
\hline SELGD & 0,9764244 & 1 & 1 \\
\hline SKPLC & 0,4507831 & $\mathbf{0}$ & $\mathbf{0}$ \\
\hline TATKS & 0,8793813 & 1 & 1 \\
\hline TBORG & 0,2522675 & $\mathbf{0}$ & $\mathbf{0}$ \\
\hline TUKAS & $\mathbf{0 , 0 3 3 3 0 6 5 7}$ & $\mathbf{0}$ & $\mathbf{0}$ \\
\hline ULKER & 0,9792775 & 1 & 1 \\
\hline VANET & 0,03105109 & $\mathbf{0}$ & $\mathbf{0}$ \\
\hline
\end{tabular}


Ek 3: 3 Y 1l Öncesine Göre Başarısızlık Tahmin Çalışması- Logit Tahmini Karşılaştırması

\begin{tabular}{|c|c|c|c|}
\hline FİRMALAR & $\begin{array}{c}\text { ÜÇ YIL ÖNCESİNE } \\
\text { GÖRE ODDS } \\
\text { RASYOSU }\end{array}$ & $\begin{array}{c}\text { LOGIT TAHMINI } \\
\text { BAŞARI }\end{array}$ & $\begin{array}{l}\text { BAŞARISIZLIK } \\
\text { DURUMU }\end{array}$ \\
\hline AEFES & 0,9999987 & 1 & 1 \\
\hline ALYAG & 0,9871699 & 1 & 1 \\
\hline BANVT & 0,9962404 & 1 & 1 \\
\hline CCOLA & 0,9994215 & 1 & 1 \\
\hline DARDL & 0,8894879 & 1 & 1 \\
\hline ERSU & 0,9984875 & 1 & 1 \\
\hline FRIGO & 0,7437193 & 1 & 1 \\
\hline KENT & 0,3082488 & 0 & 1 \\
\hline KERVT & 0,9637242 & 1 & 1 \\
\hline KNFRT & 0,9948061 & 1 & 1 \\
\hline KRSTL & 0,9700402 & 1 & 1 \\
\hline MERKO & 0,8078396 & 1 & 1 \\
\hline MRTGG & 0,03330307 & 0 & 0 \\
\hline PENGD & 0,755742 & 1 & 1 \\
\hline PETUN & 0,9135302 & 1 & 1 \\
\hline PINSU & 0,9155792 & 1 & 1 \\
\hline PNSUT & 0,9661144 & 1 & 1 \\
\hline SELGD & 0,7020371 & 1 & 1 \\
\hline SKPLC & 0,9558458 & 1 & 1 \\
\hline TATKS & 0,9944241 & 1 & 1 \\
\hline TBORG & 0,7624315 & 1 & 0 \\
\hline TUKAS & 0,9661938 & 1 & 1 \\
\hline ULKER & 0,9997102 & 1 & 1 \\
\hline VANET & 0,2489941 & 0 & 1 \\
\hline
\end{tabular}


